\title{
A DIALOGICIDADE E OS LETRAMENTOS ACADÊMICOS
}

\section{DIALOGICITY AND ACADEMIC LITERACIES}

\begin{abstract}
Atilio Butturi Junior ${ }^{1}$
RESUMO: O presente trabalho parte das discussões sobre as esferas sóciodiscursivas e sobre os letramentos acadêmicos e tem como objetivo apresentar uma discussão que relacione o princípio dialógico bakhtiniano e as práticas de letramento no Ensino Superior. Inicialmente, conceitua-se "dialogismo" como mecanismo enunciativo geral da linguagem. Logo em seguida, descreve-se a esfera acadêmica como esfera institucional e produzida segundo gêneros secundários que tendem à estabilização e oferecem modos de autoria, de composição textual e que carregam "refrações" ideológicas específicas. Finalmente, traça-se a necessidade de se pensar o papel da dialogia nas práticas de leitura e escrita, visto que muitas vezes, no Ensino Superior, a autoria, as identidades e a apropriação dos encunciados são interditados, ora pela dificuldade de apropriação da cultura escrita por parte dos alunos/acadêmicos, ora pelas características da esfera sócio-discursiva, marcada pelos efeitos de objetividade e de apagamento dos sujeitos. Concluise, a partir dos debates, que é preciso forjar modelos de ensino e aprendizagem que levem em conta que a esfera acadêmica é espaço de produção de identidades e de circulação de poder, sendo necessário aderir à postura de "agente de letramento" para a construção de letramentos "polifônicos".
\end{abstract}

Palavras-chave: Dialogicidade. Letramentos Acadêmicos. Identidade.

ABSTRACT: This work starts with the discussions on the socio-discursive spheres and on academic literacies and aims to present an argument that relates the bakhtinian dialogic principle and literacy practices in higher education. Initially, considers himself "dialogism" as a mechanism of general declarative language. Shortly thereafter, describes the academic sphere as institutional sphere and produced under secondary genres that tend to stabilize and provide authoring modes of textual composition and carrying "refractions" specific ideological. Finally, we draw the need to consider the role of dialogic practices of reading and writing, as often in higher education, authorship, identities and ownership discourses are banned, sometimes the difficulty of appropriation of literacy by the students / scholars, now in the characteristics of the socio-discursive sphere, marked by the effects of objectivity and deletion of subjects. It follows from the discussions, it is necessary to forge models of teaching and learning that take into account the academic sphere is production space of identities and circulation of power, being necessary to adhere to the position of "agent of literacy" to the construction of literacy "polyphonic".

Keywords: Dialogicity. Academic Literacies. Identity.

\footnotetext{
${ }^{1}$ Professor Adjunto. Doutor em Linguística. E-mail: a_butri@yahoo.com.br
} 


\section{INTRODUÇÃO}

Discutir leitura e produção textual na esfera acadêmica requer que se pense sobre a proficiência dos sujeitos nas atividades de leitura e escrita e que se entenda a relação intrincada que existe entre o exercício de ler e o de produzir textos. Além disso, é imprescindível que se observe, da perspectiva interacional, as condições de produção da esfera acadêmica, as modalidades identitárias que percorrem os sujeitos e, ainda, a constituição dos discursos marcada pela dialogicidade, tomada como possibilidade de inferir a abertura do texto e do discurso há um diálogo sempre tenso e por se fazer entre enunciador, gênero, discurso, alteridade e esferas sócio-discursivas (nesse caso, o Ensino Superior) de circulação, legitimação e constituição de enunciados.

A partir de tais necessidades, o presente artigo pretende traçar uma relação entre os letramentos acadêmicos (LEA; STREET, 1998) e o dialogismo bakhtiniano (BAKHTIN, 2010), apontando para uma perspectiva de apropriação da leitura e da escrita que leve em conta o papel fundamental da identidade e da alteridade das práticas letradas no Ensino Superior. A fim de trazer à tona tais discussões, este texto está organizado em três seções: na primeira, apresenta os conceitos bakhtinianos de interação verbal e dialogicidade; na segunda, descreve a noção de esfera sócio-discursiva e de esfera acadêmica; na terceira seção, discorre-se sobre a leitura e a produção textual da perspectiva de um discurso que supõe uma dialogicidade constitutiva das práticas e dos gêneros acadêmicos e que exige que se coloque entre parênteses as leituras unívocas, subsumidas no conceito de logocentrismo.

\section{A INTERAÇÃO VERBAL E A DIALOGICIDADE}


Inicialmente, é preciso apontar que partir de uma concepção interacional da linguagem implica em sustentar que a linguagem não é nem representação especular do mundo e do pensamento, nem instrumento de comunicação objetivo. Pensar a linguagem "interacionalmente" é entendê-la como forma de ação orientada. Como "lugar de interação", a linguagem é constitutiva dos mais diferentes atos e produtoras de sujeitos e identidades, bem como de vínculos societários $(\mathrm{KOCH}, 2003)$.

Entendida a linguagem, da perspectiva interacional, como prática social situada, para tratar dos conceitos de interação verbal e de dialogicidade, optase nesta seção pelos estudos da vertente bakhtiniana. Assim, primeiramente, cabe trazer à tona o capítulo seis da segunda parte de Marxismo e Filosofia da Linguagem, em que Bakhtin/Voloshinov (2006, p.123) anuncia que "[...] a interação verbal constitui a realidade fundamental da língua." O conceito de "interação verbal" está relacionado ao de enunciado (concreto, ideológico e finito) e recobre as exigências do autor de se romper tanto como o positivismo abstrato e a concepção da língua como sistema autônomo, quanto com o subjetivismo idealista e a ideia de um sujeito expressivo e livre para cometer enunciados.

De sua parte, Bakhtin/Voloshinov pretende fazer notar que a enunciação é sempre uma atividade interacional: é produto do diálogo entre dois sujeitos organizados socialmente, que se encontram em horizontes sociais e apreciativos específicos e ideologicamente marcados. A palavra, entendida então como "signo ideológico por excelência", que reflete e refrata a realidade, necessariamente procede de um sujeito e dirige-se a outro sujeito. Bakhtin/Voloshinov (2006, p.113) apontam que a palavra é "[...] uma espécie de ponte lançada entre mim e os outros."

Da perspectiva bakhtiniana, então, uma expressão nunca pode ser subjetiva: primeiro, porque pensar o "plano da expressão" exige entender o semiótico como ideológico; depois, porque o sujeito, como locutor, só é produzido semioticamente e a estrutura da enunciação é determinada pela situação social ampla e imediata. Essa determinação é, ainda, da ordem do diálogo: com os horizontes avaliativos das esferas do cotidiano e das esferas 
institucionais; com o interlocutor, que mantém sempre uma atitude ativa responsiva, o que significa que a heterogeneidade é constitutiva de qualquer enunciação.

Por sua vez, o conceito de "dialogismo" está relacionado diretamente ao de interação, enquanto produção de sentidos que movimenta enunciação, sujeitos, esferas sócio-discursivas, horizontes apreciativos e ideológicos. O posicionamento de Bakhtin, de acordo com Brait (2012) é o de ultrapassar um modelo autônomo linguístico e inferir o enunciado como forma de interação discursiva plena, que requer uma compreensão responsiva e uma valoração, da ordem da alteridade.

Destarte, seguindo com Brait (2012), quando Bakhtin, já no livro sobre Dostoiévski, aponta o imperativo de se estudar o enunciado em termos de discurso, numa nova disciplina chamada de Metalinguística (em algumas traduções, "Translinguística), o que o autor russo tece é um discurso de amplificação: deve-se entender os limites da abordagem autônoma da língua e, a partir dela, passar às relações dialógicas, que fundamentam uma Metalinguística. Para Bakhtin (2010, p.209), grifos do autor), tal Metalinguística é o estudo de relações linguística e de relações dialógicas:

[...] as relações dialógicas são extralinguísticas. Ao mesmo tempo, porém, não podem ser separadas do campo do discurso, ou seja, da língua como fenômeno integral completo. A linguagem só vive na comunicação dialógica daqueles que a usam. É precisamente essa comunicação dialógica que constitui o verdadeiro campo da vida da linguagem. [...]

No caso da leitura e da textualização, o princípio dialógico tem efeito imediato: todo texto, tomado como enunciado, exige séries de enunciados que o antecedem e o sucedem, pois o enunciado é um elo da cadeia enunciativa e exige uma concepção ativa de resposta. Compreender um texto, então, é uma co-criação do sujeito e da heterogeneidade que o constitui e que envolve tanto avaliação quanto posicionamento ideológico. A compreensão, justamente por isso, envolve uma luta de perspectivas e, por conseguinte, que se entenda 0 movimento e a modificação como condições do diálogo (BRAIT, 2010, p.20). 
Os enunciados, por seu turno, tendem à estabilidade, conforme a natureza da interação. Assim, são tipificados na forma de gêneros do discurso, de acordo com as esferas sócio-discursivas de que tomam parte e que configuram. Os gêneros, nesse caso, tenderiam à estabilidade, diante do regime marcado pela abertura da dialogicidade. Todavia, mais do que limites rígidos e sistemáticos, a relação entre interação, gêneros e dialogicidade seria da ordem do limiar: não haveria uma apropriação definitiva ou um significado estanque, porque se trata sempre de um processo e de relações de poder.

Dada a importância da esfera para a produção de gêneros e da percepção de que a esfera acadêmica se constitui a partir de gêneros secundários e da tentativa de estabilização, a próxima seção se ocupará da descrição e conceituação da esfera e dos gêneros.

\section{A ESFERA ACADÊMICA: ORIENTAÇÕES BAKHTINIANAS}

Bakhtin entabula uma relação entre gêneros do discurso e o que chama de "esferas sócio-discursivas" ou "domínios". Para o autor, as esferas são campos de atividade e de comunicação humana. De acordo com Bakhtin (2003) cada esfera social tem uma determinada finalidade ideológico-discursiva e, portanto, um modo específico e orientado de "refratar" a realidade ( lembremos de que o signo reflete e refrata a realidade em Marxismo e Filosofia da Linguagem).

Segundo a relação entre as esferas sócio-discursivas e as ideologias simplificadamente, as "ideologias do cotidiano" e as "ideologias institucionalizadas" - pode-se propor, bakhtinianamente, que há "esferas cotidianas", ligadas à vida cotidiana, e "esferas formalizadas/institucionalizadas", ligadas aos sistemas ideológicos institucionalizados e mais sistematizados. Assim, os usos sociais da linguagem são multiformes e heterogêneos, assim como os são as esferas da atividade e comunicação humanas.

Para Bakhtin (2003), a mediação entre esferas e linguagem se dá por enunciados (orais ou escritos) concretos, únicos, irrepetíveis e heterogêneos 
que são proferidos pelos sujeitos atuantes em determinadas situações sociais de interação. Os enunciados refletem (e refratam) as condições sociais e as finalidades de cada esfera e situação sociais, regulados por aquilo que o autor chama de "gêneros do discurso". Segundo o autor (2003, p. 262), "A riqueza e a diversidade dos gêneros do discurso são infinitas porque são inesgotáveis as possibilidades da multiforme atividade humana e porque em cada campo dessa atividade é integral o repertório de gêneros do discurso, que cresce e se diferencia à medida que se desenvolve e se complexifica um determinado campo".

O conceito de "gêneros do discurso" será retomado na próxima seção. Neste momento, cabe inferir que a esfera acadêmica é uma esfera do tipo especializada/formalizada, o que implica entendê-la da perspectiva das "ideologias institucionalizadas" e, na esteira dos Novos Estudos do Letramento, como esfera mediada por letramentos dominantes/institucionais e gêneros estabilizados. Dessa perspectiva, Matêncio (2002) faz notar que o funcionamento da linguagem depende do tipo de apropriação da realidade que cada instituição é capaz de realizar. Quanto à produção dos discursos científicos e didáticos, a mesma Matêncio (2002) afirma que cada instituição determinaria seus paradigmas, suas práticas discursivas, seus gêneros e, por conseguinte a relação de simetria e dissemetria entre produtores e receptores dos discursos.

Bonini e Figueiredo (2006) resgatam o conceito de "comunidade discursiva" de Swales, no intuito de identificar os diferentes tipos de funcionamento discursivo de cada esfera institucional, que passam a entender da perspectiva da sócio-retórica. Seriam 6 características que determinariam, segundo Swales (1990 apud BONINI; FIGUEIREDO, 2006, p. 419) uma "comunidade discursiva":

1) o conjunto de objetivos públicos comuns; 2) a existência de mecanismos para comunicação entre os participantes; 3) a função do feedback, ou seja, o uso das comunicações recebidas pelos participantes, que funciona como forma de participação na comunidade; 4) a capacidade que a comunidade tem para desenvolver seus 
próprios gêneros; 5) o uso de um léxico específico; e 6) a existência de membros que possuem um conhecimento profundo do discurso e dos conteúdos que circulam na comunidade.

Os autores apontam que Swales reviu o conceito de comunidade discursiva, entendendo-o como conflituoso e atravessado pela instabilidade. Tendo isso em vista, então, o importante é estabelecer uma aproximação entre as "esferas" de Bakhtin e o conceito de "comunidade": ambos os conceitos se valem do caráter interativo das práticas sócio-discursivas, entendendo que há gêneros mais regrados conforme a especialização institucional. Ademais, os dois conceitos fazem emergir a problemática da identidade dos enunciadores, porque supõem assimetria das relações e acentos valorativos distintos de acordo com os papeis que os sujeitos ocupam na interação.

Ao se tratar a esfera acadêmica, é preciso ainda aproximá-la do chamado "discurso científico", justamente porque os diversos campos de saber e conhecimento que circulam no Ensino Superior dizem respeito ou são margeados por critérios ditos científicos. Esse critérios, como apontou Coracini (1991), são produzidos segundo regimes de convencionalidade, arbitrariedade e exigem regras políticas de legitimação. Exigem, portanto, que se produzam efeitos de sentido de objetividade e opacidade, a fim de garantir o compromisso científico com a verdade e as formas legitimadas do saber acadêmico, o que pode exigir um compromisso com a autoridade dos dizeres e com a monovocalidade. Segundo a autora, ainda, o funcionamento dos discursos científicos ligados à esfera acadêmica (a pesquisa de Coracini recorta os sujeitos e discursos do campo da Química) produz um apagamento da enunciação calcado num estratagema constante de neutralização do actante, do tempo e do espaço enunciativos e, num movimento .

\section{A LEITURA E A PRODUÇÃO TEXTUAL ACADÊMICAS}

Os Parâmetros Curriculares Nacionais de Língua Portuguesa - PCNs LP (1997, p. 53) apontam que trabalhar com leitura é uma tarefa na formação tanto de leitores quanto de escritores competentes. Os PCNs surgem, na 
educação brasileira, sob a égide da politização da leitura e da escrita, quando passou-se a repensar o papel da educação iluminista e seu potencial de transformação social (GRAFF, 1994, p.91). A leitura e a escrita, vistas como bens simbólicos a se conquistar, são relacionadas ao surgimento da primeira grande "democratização" das letras, intimamente ligada ao desenvolvimento do capital industrial e à necessidade de especialização da mão-de-obra, travestida em missão de salvamento e inclusão: "[...] a aquisição destes conhecimentos é conditio sine qua non de salvação ou transformação." (GERALDI, 1999, p.34).

$\mathrm{Na}$ esfera acadêmica, o trabalho com a leitura e a produção textual tem se desenvolvido à luz dos chamados Novos Estudos do Letramento e de uma metodologia muitas vezes baseada nos gêneros discursivos. Essa tomada de posição faz inferir que os processos de leitura e produção textual são considerados interacionais, plásticos e relacionados às instâncias de usos da linguagem, das posições de sujeito e de identidade e da assunção do caráter heterogêneo dos textos. No que tange à "democratização" da cultura dita letrada, sobretudo relacionada à emergência de uma "nova clientela" no Ensino Superior, resultado dos processos hodiernos de ampliação de vagas no Brasil, alguns trabalhos (BONINI; FIGUEIREDO, 2006; MATÊNCIO, 2002, BAGNO; REIS, 2011) têm demonstrado algumas das dificuldades de apropriação dos usos da escrita altamente formalizados e dos processos de negociação identitária que percorrem as práticas letradas no Ensino Superior.

Cabe notar que os eventos e práticas de letramento que ali acontecem exigem gêneros sobretudo secundários. Nessa esfera, os gêneros têm sempre finalidades definidas, concepções de autoria e destinatários específicos. Os eventos de letramento acadêmico envolvem gêneros do discurso. Esses gêneros se pautam pelo discurso da objetividade e pelas produção de efeitos de sentido de autonomia e opacidade, tomam lugar com finalidades de circulação e legitimação do discurso acadêmico-científico. No interior do discurso acadêmico, a leitura e a produção de textos, sob a égide dos gêneros, traria uma concepção de autoria cindida entre a exigência dialógica da linguagem, conforme os apontamentos interacionistas, e o agenciamento discursivo monovocalizado, típico da comunidade discursiva acadêmica, que 
tende a enunciados parafrásticos e de repetição. Essa relação de autoria, seguindo Gee (1996), forneceria a classificação entre insiders e outsiders, de acordo com a capacidade de saber-fazer com os textos, discursos e com 0 ethos exigido pela comunidade discursiva acadêmica.

Finalmente, os destinatários, subsumidos das concepções de dialogismo e de atitude ativa responsiva (BAKHTIN; VOLOSHINOV, 2006), seriam os pares acadêmicos, que entabulariam com os enunciadores/autores relações de simetria - discente/discente, pesquisador/pesquisador - ou relações de dessimetria - tipicamente, aquelas encontradas em sala de aula, que perfazem a relação discente/docente. Tais posições poderiam ser sempre passíveis de modificação, partindo-se dos pressupostos aventados por Kleiman (2007) de que as identidades dos professores podem ser negociadas e, segundo a perspectiva do letramento, açambarcarem práticas locais e minoritárias em movimentos de valorização e assunção da diversidade. Para Kleiman, então, a posição passaria a ser a de "agente de letramento", que ultrapassaria a suposta autonomia e neutralidade das alcunhas de "mediação".

Da perspectiva dialógica da leitura, Geraldi (1997), ao reconhecer que ler é construir sentidos em um seu contexto social de uso, entende que tal relação demanda um mínimo de polifonia, de vozes dissonantes. Todavia, na leitura e na produção textual acadêmicas, muitas vezes há um apagamento das vozes dos leitores, já que o interdiscurso científico exige que se assumam certos pontos de vista como verdadeiros - uma das condições da pertença ao Discurso, nos termos de Gee (1996). Neste caso, ser proficiente na leitura dos textos acadêmico requer que se reconheça, por um lado, o caráter institucional dos dizeres que circulam nessa esfera social e, por outro, que se estabeleça um diálogo ativo com os textos na modalidade dos enunciados bakhtinianos.

No que se refere propriamente à leitura, Coracini (2005) sugere uma escansão para se observar esse vasto campo de estudos: de um lado, teríamos concepções modernas de leitura, que se pautariam na crença numa espécie de sujeito transcendental e numa concepção de texto autônomo. A modernidade na leitura seria representada por dois grandes modelos: o da leitura como decodificação e o da leitura como interação. 
No primeiro grande agrupamento teórico, estaria a "perspectiva do estruturalismo" (CORACINI, 2005, p. 20), que subsume teorias que constroem a leitura como objeto a partir do texto entendido como unidade estruturada. Já o segundo dos agrupamentos, o interativo, é descrito como aquele que exige um sujeito ativo e consciente, capaz de entender as marcas deixadas por textos também passíveis de saturação. Neste último caso, ainda, é necessário marcar que haveria leituras autorizadas, ora pela autoria, ora pelas pistas textuais. Os modelos interativos não se referem à teoria bakhtiniana, pois, não obstante a amplificação dos conceitos de uso, contexto e enunciação, não dariam conta de se pensar a presença da alteridade constitutiva nas leituras.

Coracini (2005, p.22), adiante, descreve então o que chama de "perspectiva da (pós-) modernidade", caracterizada pela leitura vista como "processo discursivo". Neste caso, "discursivo" abre um rol de categorias que a autora não define com precisão, mas que estão diretamente ligadas aos estudos do sujeito do inconsciente, da ideologia, da incompletude e da heterogeneidade. O que a pesquisadora elabora é uma classificação teórica de leitura cujo cerne está numa aproximação entre os discursos que a investigam da perspectiva de uma produção constante, negando tanto a possibilidade de un sujeito autônomo, quanto colocando em xeque os discursos da autoria e da autotelia do texto. Aqui, Coracini (2005) entende que residiriam as qualidades de teorias como a bakhtiniana, no que se pese a presença do dialogismo e da heterogeneidade.

Não obstante tais dificuldades, a função precípua dessas classificações pós-modernas de (CORACINI, 2005), na qual se pode incluir os pressupostos dialógicos, sugerem um ultrapassamento ou, ao menos, um ponto de inflexão diante das teorias de modelos ditos "logocêntricos", e que acabam por definir e separar o discurso verdadeiro e as leituras possíveis, contendo a disseminação. O que se teria, de acordo com essas concepções pósmodernizantes - e não obstante certos desacertos epistemológicos - é um modelo de tensionamento e abertura da ordenação das leituras.

Estendendo as discussões sobre o logocentrismo para a leitura e a textualização na esfera acadêmica, poder-se-ia dizer que o logocentrismo se 
constituiria nas posições de institucionalização de gêneros como gramáticas generificantes, nos modelos de produção de textos e leituras de textos dito acadêmicos, como resumo, resenha, artigo, tese etc. -, e em modelos (paradigmas) de pesquisa, que recortam mundos possíveis, o que poder ser lido, o que pode ser dito e quais são as identidades que devem ser assumidas pelos sujeitos na universidade. Dessa perspectiva, o inacabamento da linguagem estabelecido pela teoria dialógica bakhtiniana, seria um modelo para, a partir das discussões sócio-interacionistas, perceber a matriz logocêntrica da crença nos dogmas da Ciência e a "submissão" das identidades de autor e leitor aos sentidos científicos já (supostamente) dados nos textos que circulam com legitimidade na esfera acadêmica.

Se, finalmente, a esfera acadêmica pode ser tomada como uma instituição que é percorrida por séries de discursos legitimados e cuja memória discursiva remete ao embate pelo poder de dizer o verdadeiro, a heterogeneidade constitutiva dos enunciados, aventada por Bakhtin - e mais tarde transposta em teorias do discurso e teorias enunciativas - deve ser aproximada das formas mostradas da presença do outro nos discursos acadêmicos. Dito de outra forma, mais do que assumir a presença dos autores de cada campo do conhecimento e do saber como condição da textualidade nos moldes das teorias de textualidade e de intertextualidade -, cabe a uma discussão dialógica de leitura e escritura acadêmicas se pautar pela busca das vozes que, silenciadas ou tornadas opacas, produzem a comunicação formal, especializada e supostamente objetiva do Ensino Superior.

\section{CONSIDERAÇÕES FINAIS}

Este trabalho teve por objetivo traçar relações entre a teoria dialógica e os letramentos acadêmicos. Para isso, conceituou inicialmente o "dialogismo" e, adiante, refletiu sobre a esfera acadêmica e o papel que o princípio dialógico desempenhava nos letramentos.

Fundamentalmente, as discussões exigem que se construam processos de ensino e aprendizagem de leitura e escrita no Ensino Superior que se 
pautem pela assunção da diversidade e pela exigência de apropriação efetiva das modalidades de autoria que os estudos superiores demandam.

Dessa perspectiva, o papel do professor, aos moldes de Kleiman, é o do "agente de letramento", que não apenas forja um modelo de aculturação mas constroi práticas que tornam possível que as vozes surjam e se adensem, entendendo que o trabalho com a escrita é sempre um processo de produção de sujeitos, identidades e relações de poder e força.

\section{REFERÊNCIAS BIBLIOGRÁFICAS}

BAGNO, M.; REIS, D. da S. A prática de reescrita na produção textual acadêmica. DLCV, João Pessoa, v.8, n. 1, p. 103-116, jan./jun 2001.

BAKHTIN, M. Estética da criação verbal. 4. ed. Tradução de Paulo Bezerra. São Paulo: Martins Fontes, 2003.

Problemas da poética de Dostoiévski. 5.ed. Tradução de Paulo

Bezerra. Rio de Janeiro: Forense Universitária, 2010.

(VOLOSHINOV). Marxismo e filosofia da linguagem: problemas fundamentais do método sociológico na ciência da linguagem. 12.ed. São Paulo: Hucitec, 2006.

BONINI, A.; FIGUEIREDO, D. de C. práticas discursivas e ensino do textoacadêmico: concepções de alunos de mestrado sobre a escrita. Linguagem em (Dis)curso, Tubarão, v. 6, n. 3, p. 413-446, set./dez. 2006.

BRAIT, B. Perspectiva dialógica. In: BRAIT, B.; SOUZA-E-SILVA, M. C. (Orgs.). Texto ou discurso? São Paulo: Contexto, 2012. p. 9-29.

CORACINI, M. J. R. F. Concepções de leitura na (pós-)modernidade. In: CARVALHO, R. C de; LIMA, P. (Org.): Leitura: múltiplos olhares. Campinas, SP; Mercado de Letras; São João da Boa Vista, SP: Unifeob, 2005. p. 15-44.

. Um fazer persuasivo: o discurso subjetivo da Ciência. São Paulo: EDUC; Campinas: Pontes, 1991.

GEE, J. P. Social linguistics and literacies: ideology in Discourses. 2.ed. London; Philadelphia: The Farmer Press, 1996.

GERALDI, J. W. Portos de passagem. 4. ed. São Paulo: Martins Fontes,1999. 
LEA, M. R.; STREET, B. Student writing in higher education: an academic literacies approach. Studies in higher education, v.23, n.2, p.157-172, jun. 1998.

KLEIMAN, A. Professores e agentes de letramento: identidade e posicionamento social. Filologia, São Paulo, p. 409-424, 2007.

KOCH, I. V. A interação pela linguagem. 8.ed. São Paulo: Contexto, 2003.

MATÊNCIO, M. de L. M. Atividadesde (re)textualização em práticas acadêmicas: um estudo do resumo. Scripta, Belo Horizonte, v. 6, n. 11, p. 109122, 2. sem. 2002. 